\title{
Strukturalna dziedziczność w procesach napawania
}

\section{Structure-heredity in surfacing processes}

\section{Streszczenie}

Termin strukturalna dziedziczność oznacza, że przy zbliżonym składzie chemicznym, ale różnej strukturze wyjściowych materiałów wsadowych, a także przy praktycznie jednakowych warunkach topienia i stygnięcia materiału roztopionego, otrzymany metal w stanie stałym ma różną mikro- i makrostrukturę, jakby przekazaną przez materiał roztopiony strukturę wyjściowych materiałów wsadowych. W artykule przytoczono wyniki badań wpływu wyjściowej struktury materiałów dodatkowych do napawania na strukturę i właściwości metalu napawanego różnymi metodami. Stwierdzono, że w największym stopniu efekt strukturalnej dziedziczności można wykorzystać w tych metodach napawania, w których temperatura jeziorka spawalniczego jest daleka od równoważnej i można ją regulować na drodze podawania materiału dodatkowego: napawanie plazmowo-proszkowe, napawanie elektrożużlowe nieciągłymi materiałami itp.

\section{Wstęp}

W metalurgii wpływ struktury i właściwości materiałów wyjściowych materiałów wsadowych na materiał roztopiony, a przez niego na strukturę i właściwości nowo otrzymanego metalu w stanie stałym zbadano dostatecznie szczegółowo $[1 \div 7]$. W tych przypadkach, gdy przy zbliżonym składzie chemicznym, ale różnej strukturze wyjściowych materiałów wsadowych, a także przy jednakowych w przybliżeniu warunkach topienia i następnie stygnięcia materiału roztopionego otrzymuje się metal w stanie stałym z różną mikro- i makrostrukturą, jakby przekazaną przez materiał roztopiony ze struktury wyjściowych materiałów wsadowych, używany jest termin strukturalna dziedziczność [3].

Dr hab. inż. Igor A. Riabcew - Instytut Spawania Elektrycznego im. E.O. Patona, Kijów, Ukraina.
Wiadomo, że pod względem swoich właściwości i budowy ciecze znajdują się znacznie bliżej ciał sta-

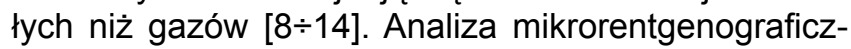
na pokazuje, że przy temperaturze niezbyt przekraczających temperaturę topnienia rozmieszczenie cząstek w cieczy nie jest bezładne, lecz bardzo podobne do istniejącego w krystalicznym ciele stałym [1]. Jednak w odróżnieniu od krystalicznych ciał stałych, których struktura charakteryzuje się uporządkowaniem dalekiego zasięgu, podstawową charakterystyką struktury cieczy jest uporządkowanie bliskiego zasięgu,

Co jest uwzględniane przez model klastrowy struktury cieczy. Klastrami nazywane są obszary z określonym typem uporządkowania przestrzennego cząstek w cieczy. W każdym momencie centralna część klastrów jest zbliżona do ciała stałego, podczas gdy zewnętrzne warstwy są pozbawione ścisłej symetrii. Przy tym klastry strukturalnie i genetycznie są związane $z$ ciałem stałym.

Proces krystalizacji roztopionego materiału może przebiegać przez przyłączanie do niego grup klastrów. 
Struktura roztopionego materiału, wpływajac na mechanizm krystalizacji, w określonym stopniu wyznacza także wadliwość kryształu. Można przypuszczać, że stop bardziej mikroniejednorodny i nierównoważny tworzy także najbardziej wadliwe kryształy [1]. Oddziałując na strukturę wyjściowych materiałów wsadowych można osiągnąć istotne zwiększenie jakości zakrzepłego metalu i jego właściwości.

Analiza wykonała, że w odróżnieniu od metalurgii, badanie strukturalnej dziedziczności w układzie wyjściowy materiał elektrodowy (dodatkowy) - ciekły metal jeziorka spawalniczego - metal w stanie stałym jest utrudnione w wyniku następujących charakterystycznych cech napawania (spawania):

- nagrzewanie, topienie i przenoszenie materiału elektrodowego (dodatkowego) w różnych metodach napawania znacznie się różni w zależności od parametrów procesu;

- parametry temperaturowo-czasowe jeziorka spawalniczego w różnych metodach napawania też znacznie się różnią, nie są stacjonarne oraz są trudno regulowalne, wskutek czego ciekły metal jeziorka spawalniczego będzie daleki od równoważnego;

- istotny jest wpływ materiału podstawowego, który w stanie ciekłym dostaje się do jeziorka spawalniczego i może zmieniać strukturę oraz właściwości napawanego metalu;

- krystalizacja metalu jeziorka spawalniczego zachodzi na podłożu stałym, którego struktura wpływa na strukturę i właściwości napawanego metalu.

W artykule przytoczono wyniki badań wpływu wyjściowej struktury materiałów dodatkowych do napawania na strukturę i właściwości metalu napawanego dwoma najbardziej charakterystycznymi metodami: łukową elektrodą topliwą i plazmowo-proszkową.

\section{Przebieg i wyniki badań}

Analizie poddano niektóre cechy szczególne nagrzewania, topienia i przenoszenia materiału elektrodowego i dodatkowego, które wyznaczają temperaturowo-czasowe parametry jeziorka spawalniczego dla tych metod napawania.

Przy łukowym napawaniu elektrodą topliwą charakter przenoszenia materiału elektrodowego jest wyznaczony przez układ sił działających na ciekłą kroplę na powierzchni czołowej elektrody. Podstawowe z nich to: siła ciążenia, siła napięcia powierzchniowego, siły elektromagnetyczne, siła reakcyjna par metalu, siła aerodynamiczna oraz ciśnienie gazów i par tworzących się wewnątrz kropel. Wielkość tych sił i kierunek działania ich wypadkowej w znacznym stopniu zależą od parametrów jarzenia łuku, składu materiału elektrodowego i środowiska osłonowego, stanu powierzchni i średnicy elektrody oraz charakterystyk źródła prądu spawania.

Przy napawaniu (spawaniu) łukowym nagrzewanie materiału elektrodowego zachodzi przede wszystkim dzięki ciepłu wydzielającemu się w przyelektrodowym obszarze łuku, a prędkość topienia się elektrody jest proporcjonalna do natężenia prądu spawania [15, 16]. Temperatura kropel metalu elektrodowego zawsze przewyższa jego temperaturę topnienia. Na przykład przy spawaniu niskowęglowym drutem stalowym łukiem krytym wynosi ona $2270 \pm 100 \mathrm{~K}$, nieznacznie zmieniając się w szerokim przedziale natężenia prądu i napięcia łuku [17].

Przy napawaniu plazmowo-proszkowym (NPP) i niektórych innych metodach napawania jest przeciwnie, charakterystyki przenoszenia nie są wprost związane $z$ natężeniem prądu i napięciem łuku, ale znacząco zależą od składu frakcyjnego i masowej prędkości podawania materiału dodatkowego oraz jego właściwości fizycznych.

Przy plazmowym napawaniu proszkiem określonej frakcji następuje równomierne przenoszenie materiału dodatkowego przez przestrzeń łuku. Jednak pewna część materiału dodatkowego przy NPP może dostawać się do jeziorka ciekłego metalu w stanie ciekłostałym lub stałym. Średnia temperatura cząstek proszku dostarczonych do jeziorka spawalniczego zmienia się w szerszym zakresie niż temperatura kropel metalu elektrodowego przy napawaniu łukowym, od $(0,2 \div 0,3) T_{\text {topnienia }}$ do $T_{\text {wrzenia }}$. W wyniku zmieniają się parametry temperaturowo-czasowe jeziorka spawalniczego i ten czynnik może w znaczącym stopniu wpływać na strukturę i właściwości napawanego metalu.

Sterować nagrzewaniem proszku, jak i jego masową prędkością podawania można, nie zmieniając mocy łuku [18]. Brak bezpośredniego sprzężenia natężenia prądu łuku i wydajności topienia materiału dodatkowego jest jedną z charakterystycznych cech NPP. O ile przy napawaniu łukowym współczynnik proporcjonalności między natężeniem prądu i masową prędkością topienia elektrody (współczynnik stapiania $\alpha_{\text {st }}$ ) zależy od energetycznych charakterystyk łuku i właściwości samej elektrody, o tyle przy NPP maksymalna wydajność topienia materiału dodatkowego (przy zadanym natężeniu prądu) istotnie zależy także od czynników określających stan cieplny w jeziorku spawalniczym: właściwości cieplno-fizycznych i temperatury podgrzewania materiału podstawowego, masy napawanego elementu, prędkości napawania itd. Tłumaczy się to tym, że w przypadku NPP część mocy cieplnej łuku wprowadzanej do materiału podstawowego powinna zużywać się na topienie proszku, który może dostawać się do jeziorka spawalniczego, będąc nagrzany do temperatury niższej od temperatury topnienia $\left(T_{\text {topnienia }}\right)$. $Z$ tego powodu im mniejsza jest intensywność odprowadzania ciepła z jeziorka spawalniczego do materiału podstawowego, tym większa ilość proszku może być roztopiona przy stałym natężeniu prądu napawania.

Przy napawaniu łukowym elektrodą topliwą badano wpływ kompozycji węglikowych o wymiarach materiałów nanostrukturalnych, wprowadzanych do wsadu drutów proszkowych, na strukturę i właściwości 
Tablica I. Skład chemiczny i twardość stopiwa doświadczalnych drutów proszkowych

Table I. Experimental flux wire chemical composition and weld metal hardness

\begin{tabular}{|c|c|c|c|c|c|c|c|c|c|}
\hline \multirow{2}{*}{ Gatunek drutu proszkowego } & \multirow{2}{*}{$\begin{array}{l}\text { Oznaczenie } \\
\text { umowne }\end{array}$} & \multicolumn{7}{|c|}{ Zawartość pierwiastków, \% mas. } & \multirow{2}{*}{$\begin{array}{c}\text { Twardość } \\
\text { HRC }\end{array}$} \\
\hline & & C & $\mathrm{Mn}$ & $\mathrm{Si}$ & $\mathrm{Cr}$ & W & Mo & $\mathrm{V}$ & \\
\hline PP-Np-35V9H3GSF & Op-1 & 0,39 & 0,60 & 1,0 & 2,97 & 8,05 & - & 0,70 & 51 \\
\hline PP-Np-35V9H3GSF & Op-2 & 0,34 & 0,60 & 1,0 & 3,0 & 9,30 & - & 0,76 & 54 \\
\hline PP-Np-30H4V2M2FS & Op-3 & 0,37 & 0,72 & 1,17 & 3,97 & 2,52 & 1,88 & 0,44 & 55 \\
\hline PP-Np-30H4V2M2FS & Op-4 & 0,35 & 0,70 & 1,17 & 3,80 & 2,33 & 1,97 & 0,45 & 53 \\
\hline
\end{tabular}

napawanego metalu. Nanowymiarowe kompozycje węglikowe otrzymywano na drodze wysokotemperaturowej obróbki w atmosferze CO proszków wysokowęglowego żelazochromu FCh800, żelazowanadu FVd50 i wolframu [19].

Nanowymiarowe kompozycje węglikowe zastosowano we wsadzie drutów proszkowych PP-Np35V9H3GSF i PP-Np-30H4V2M2FS, przeznaczonych do napawania narzędzi do obróbki plastycznej metali na gorąco i zapewniających otrzymanie stopiwa typu żaroodpornych stali matrycowych. Drut proszkowy PP-Np-35V9H3GSF wykonano w dwóch wariantach: Op-1 - standardowy wsad zawierający nieobrobiony proszek wolframu; Op-2 - wsad z zastosowaniem obrobionego proszku wolframu. Drut proszkowy PP-Np$30 \mathrm{H} 4 \mathrm{~V} 2 \mathrm{M} 2 \mathrm{FS}$ także wykonano $w$ dwóch wariantach: Op-3 - standardowy wsad; Op-4 - wsad z zastosowaniem obrobionego proszku żelazochromu i żelazowanadu. Obliczeniowy skład chemiczny wsadu drutów proszkowych korygowano tak, aby otrzymać stopiwo o jednakowym składzie chemicznym.

Przy użyciu doświadczalnych drutów proszkowych napawano próbki, określono skład chemiczny stopiwa i jego twardość (tabl. I).

Badania metalograficzne wykazały, że mikrostruktura metalu napawanego standardowym drutem Op-1 jest martenzytem listwowym o mikrotwardości HV0,5 = $5930 \mathrm{MPa} z$ niewielką ilością austenitu szczątkowego o twardości HV0,5 = 5090 $\div 490 \mathrm{MPa}$ (rys. 1a). W strukturze napawanego metalu występują także wtrącenia węglików. Mikrostruktura metalu napawanego doświadczalnym drutem Op-2 ulega zmianie: jednocześnie $z$ martenzytem listwowym pojawia się martenzyt płytkowy, przy czym jego płytki mają kształt soczewkowy (rys. 1b). Martenzyt ma twardość HV0,5 = $5930 \mathrm{MPa}$. llość austenitu szczątkowego jest nieco większa niż $w$ metalu napawanym drutem standardowym, a jego twardość wynosi HV0,5 = 4410 $\div 5490 \mathrm{MPa}$. Wprowadzenie do wsadu doświadczalnego drutu proszkowego składników zawierających nanowymiarowe węgliki prowadzi do rozdrobnienia struktury napawanego metalu.

Mikrostrukturę metalu napawanego standardowy drutem proszkowym Op-3 przedstawiono na rysunku 1c. Matryca zawiera głównie martenzyt li-

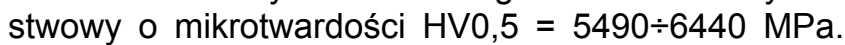
$\mathrm{Na}$ granicach ujednorodnienia austenit szczątkowy $(\mathrm{HV} 0,5=5020 \div 5090 \mathrm{MPa})$. Mikrostrukturę metalu

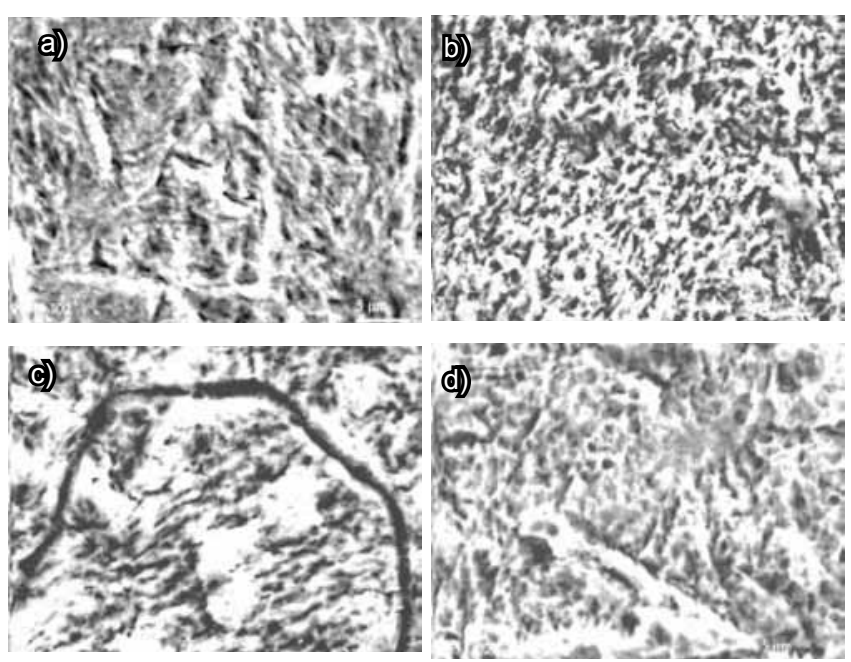

Rys. 1. Mikrostruktura metalu napawanego drutami proszkowymi: a) standardowy drut Op-1, b) drut doświadczalny Op-2, c) standardowy drut Op-3, d) drut doświadczalny Op-4, pow. 2400x

Fig. 1. Microstructure of flux wire surfacing by welding metal: a) standard wire Op-1, b) experimental wire Op-2, c) standard wire Op-3, d) experimental wire Op-4, magn. $2400 x$

napawanego doświadczalnym drutem proszkowym Op-4 przedstawiono na rysunku $1 \mathrm{~d}$.

Ta struktura, w porównaniu ze strukturą standardowego napawanego metalu 30H4V2M2FS, jest bardziej rozdrobniona, odcinków martenzytu listwowego jest zauważalnie mniej, przeważa martenzyt płytkowy. Twardość martenzytycznej matrycy wynosi HV0,5 = $5490 \mathrm{MPa}$. Ilość austenitu szczątkowego jest mniejsza niż przy napawaniu drutem standardowym, mikrotwardość austenitu szczątkowego wynosi HV0,5 = 4120-4660 MPa.

Badania odporności na zmęczenie cieplne przeprowadzano na urządzeniu i wg metodyki [20], przewidującej nagrzewanie napawanej powierzchni próbki o wymiarach $40 \times 40 \times 40 \mathrm{~mm}$ palnikiem gazowym do $800^{\circ} \mathrm{C}$ (plamka nagrzewania o średnicy $15 \mathrm{~mm}$ ) i chłodzenie strumieniem wody do $60^{\circ} \mathrm{C}$. Cykle nagrzewanie-chłodzenie powtarzano do pojawienia się siatki pęknięć w wyniku zmęczenia cieplnego. Wyniki badań przedstawiono w tablicy II.

Badania odporności na zmęczenie cieplne wykazały, że zastosowanie we wsadzie drutów proszkowych nanowymiarowych kompozycji węglikowych zwiększa odporność napawanego metalu - wzrasta liczba 
Tablica II. Odporność na zmęczenie cieplne napawanego metalu Table II. Thermal endurance of surfaced metal

\begin{tabular}{|c|c|c|}
\hline \multirow[b]{2}{*}{$\begin{array}{c}\text { Gatunek } \\
\text { drutu proszkowego }\end{array}$} & \multicolumn{2}{|c|}{ liczba cykli cieplnych } \\
\hline & $\begin{array}{c}\text { do pojawienia } \\
\text { się siatki } \\
\text { pęknięć }\end{array}$ & $\begin{array}{c}\text { do początku } \\
\text { rozwoju siatki } \\
\text { pęknięć }\end{array}$ \\
\hline PP-Np-35V9H3GSF (Op-1) & 60 & 80 \\
\hline PP-Np-35V9H3GSF (Op-2) & 70 & 100 \\
\hline PP-Np-30H4V2M2FS (Op-3) & 40 & 60 \\
\hline PP-Np-30H4V2M2FS (Op-4) & 60 & 80 \\
\hline
\end{tabular}

Tablica III. Zużycie napawanych próbek przy tarciu metal-metal w podwyższonej temperaturze

Table III. Metal-metal - abrasive wear of surfaced samples in increased temperature

\begin{tabular}{|c|c|c|}
\hline \multirow{2}{*}{$\begin{array}{c}\text { Gatunek } \\
\text { drutu proszkowego }\end{array}$} & \multicolumn{2}{|c|}{ Zużycie, $\mathrm{kg} / \mathrm{km} \cdot 10^{-4}$} \\
\cline { 2 - 3 } & $\begin{array}{c}\text { napawanej } \\
\text { próbki }\end{array}$ & $\begin{array}{c}\text { przeciw- } \\
\text { próbki }\end{array}$ \\
\hline PP-Np-35V9H3GSF (Op-1) & 2,9705 & 37,7625 \\
\hline PP-Np-35V9H3GSF (Op-2) & 2,4589 & 28,1803 \\
\hline PP-Np-30H4V2M2FS (Op-3) & 2,7429 & 33,8164 \\
\hline PP-Np-30H4V2M2FS (Op-4) & 2,4527 & 17,6991 \\
\hline
\end{tabular}

cykli nagrzewanie-chłodzenie do pojawienia się i rozwoju siatki pęknięć zmęczenia cieplnego.

Badania odporności na zużycie w warunkach tarcia ślizgowego metal-metal w podwyższonej temperaturze wykonano wg następującej metodyki: podczas badań napawana próbka o wymiarach $10 \times 17 \times 40 \mathrm{~mm}$ jest dociskana z siłą 171,6 N (17,5 kG) do obracającego się z prędkością $30 \mathrm{obr} / \mathrm{min}$ pierścienia-przeciwpróbki o średnicy $120 \mathrm{~mm}$, wykonanego ze stali 45 i nagrzewanego podczas badań palnikiem gazowym. Temperatura w strefie styku próbki i przeciwpróbki wynosi $600^{\circ} \mathrm{C}$, czas trwania badań - 1 godzina. W trakcie badań próbka wykonuje ruchy postępowo zwrotne w płaszczyźnie pionowej, amplituda ruchów wynosi $20 \mathrm{~mm}$, a częstotliwość - $62 \mathrm{~min}^{-1}$ [20]. Wyniki badań przytoczono w tablicy III.

Badania wykazały, że zużycie metalu napawanego drutami proszkowymi ze wsadem doświadczalnym jest mniejsze niż zużycie próbek napawanych drutami ze wsadem standardowym. Mniejsze jest także zużycie pierścieni-przeciwpróbek, które były badane w parze z próbkami napawanymi drutami proszkowymi ze wsadem doświadczalnym.

Jak wskazano, znaczna nierównomierność nagrzewania proszku w łuku plazmowym, możliwość dostania się do jeziorka spawalniczego nieroztopionych cząstek powinny wpływać na jego rozmiary, mase i temperaturę, a także na charakter krystalizacji, strukturę i właściwości napawanego metalu.

Badano strukturę proszku PG-10R6M5 różnych frakcji i jej wpływ na strukturę metalu napawanego plazmowo-proszkowo [21]. Badano strukturę proszku PG-10R6M5 frakcji minimalnego stosowanego do napawania rozmiaru $40 \div 50 \mu \mathrm{m}$ (rys. 2) oraz maksymalnego rozmiaru $250 \div 315 \mu$ m (rys. 3 ).

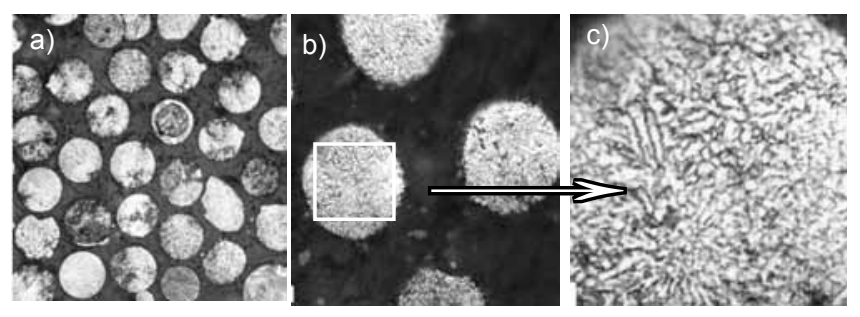

Rys. 2. Mikrostruktura cząstek proszku PG-10R6M5 o ziarnistości $50 \mu \mathrm{m}$ : a) 200x, b) 630x, c) 2000x

Fig. 2. Microstructure of flux powder PG-10R6M5 elements with grain size $50 \mu \mathrm{m}$ : a) 200x, b) 630x, c) 2000x

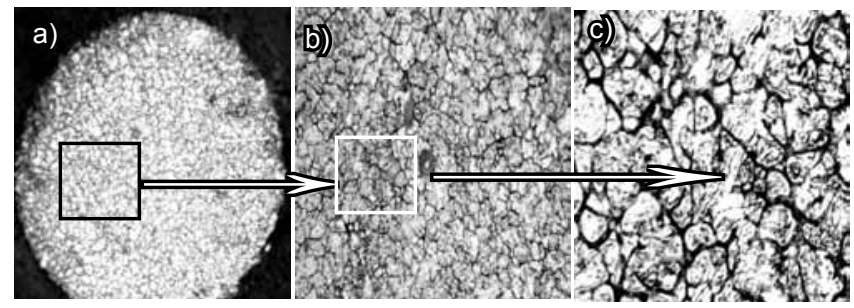

Rys. 3. Mikrostruktura cząstek proszku PG-10R6M5 o ziarnistości 250 um: a) 320x, b) 800x, c) 2000x

Fig. 3. Microstructure of flux powder PG-10R6M5 elements with grain size $250 \mu \mathrm{m}$ : a) $320 \mathrm{x}$, b) $800 \mathrm{x}$, c) $2000 \mathrm{x}$

Stwierdzono, że frakcja proszku $40 \div 50 \mu \mathrm{m}$, która krystalizuje podczas otrzymywania proszku z większą prędkością, ma bardzo drobną strukturę i z trudem identyfikuje się ją nawet przy powiększeniu 2000x (rys. 2c). Przy takim powiększeniu w strukturze widoczne są dendryty, głównie orientowane do środka cząstki proszku i składowa eutektyczna na granicach ziaren. Struktura proszku PG-10R6M5 frakcji 200 $\div 315 \mu \mathrm{m}$ charakteryzuje się ziarnem o większych wymiarach różnej orientacji, i jest zbliżona do struktury staliw szybkotnącego 10R6M5 (rys. 3b). Przy większym powiększeniu na granicach ziaren występują wydzielenia składowej eutektycznej, a wewnątrz ziaren widoczne są igły martenzytu i austenit szczątkowy (rys. 3c).

Przeprowadzono analizę rentgenostrukturalną proszku PG-10R6M5 różnych frakcji oraz metalu napawanego tym proszkiem metodą plazmową (tabl. IV). Jeżeli w strukturze proszku drobnoziarnistej frakcji przeważa faza y (jej zawartość wynosi $59,88 \%$ ), to w strukturze gruboziarnistego proszku odwrotnie, więcej jest fazy $\alpha-55,14 \%$ (faza a składa się z martenzytu i ferrytu). W obydwu frakcjach proszku w strukturze nie występują wydzielenia węglików prawdobodobnie są one tak małe, że nie są wykrywane daną metodą.

W napawanym metalu następuje zwiększenie zawartości fazy $\alpha$, lecz ponieważ jej zawartość była większa w proszku o większych wymiarach, to $w$ metalu napawanym tym proszkiem zawartość $\alpha$-fazy jest także większa. W napawanym metalu pojawiają się wtrącenia węglików i ich ilość jest różna: więcej wtrąceń węglików występuje w metalu napawanych proszkiem drobniejszych frakcji.

Oceniając wg zawartości fazy a i y można stwierdzić, że przy napawaniu plazmowo-proszkowym obserwuje się określone dziedziczenie struktury 
Tablica IV. Wyniki analizy rentgenowskiej struktury proszku PG-10R6M5 różnych frakcji oraz metalu napawanego tym proszkiem Table IV. Results of X-ray radiography analysis of flux powder PG-10R6M5 structure of different fraction and surfaced those flux powder metals

\begin{tabular}{|c|c|c|c|c|}
\hline $\begin{array}{l}\text { Badany } \\
\text { materiał }\end{array}$ & $\begin{array}{c}\text { Frakcja } \\
\mu \mathrm{m}\end{array}$ & $\begin{array}{l}\text { Zawartosć fazy } \alpha, \% \text { mas. } \\
\text { parametr siatki a, nm }\end{array}$ & $\begin{array}{l}\text { Zawartosć fazy y, \%mas. } \\
\text { parametr siatki a, nm }\end{array}$ & $\begin{array}{c}\text { Typ i zawartość węglików, \%mas. } \\
\text { parametry siatki a, c,nm }\end{array}$ \\
\hline $\begin{array}{l}\text { Proszek } \\
\text { PG-10R6M5 }\end{array}$ & $40-50$ & $\begin{array}{c}\alpha=40,12 \\
a=0,2885\end{array}$ & $\begin{array}{l}Y=59,88 \\
a=0,3626\end{array}$ & - \\
\hline $\begin{array}{l}\text { Metal napawany } \\
\text { 10R6M5 }\end{array}$ & $40-50$ & $\begin{array}{l}\alpha=51,57 \\
a=0,2882\end{array}$ & $\begin{array}{l}y=43,36 \\
a=0,3610\end{array}$ & $\begin{array}{c}\mathrm{Mo}_{2} \mathrm{C}=5,07 \\
\mathrm{a}=0,2939 ; \quad c=0,4645\end{array}$ \\
\hline $\begin{array}{l}\text { Proszek } \\
\text { PG-10R6M5 }\end{array}$ & $250-315$ & $\begin{array}{l}\alpha=55,14 \\
a=0,2897\end{array}$ & $\begin{array}{l}y=44,86 \\
a=0,3624\end{array}$ & - \\
\hline $\begin{array}{l}\text { Metal napawany } \\
\text { 10R6M5 }\end{array}$ & $250-315$ & $\begin{array}{c}\alpha=62,83 \\
a=0,2892\end{array}$ & $\begin{array}{l}y=34,45 \\
a=0,3623\end{array}$ & $\begin{array}{c}\mathrm{Mo}_{2} \mathrm{C}=2,72 \\
\mathrm{a}=0,2959 ; \quad c=0,4665\end{array}$ \\
\hline
\end{tabular}

Tablica V. Wpływ dodatku proszku frakcji o większej ziarnistości na mikrostrukturę napawanych ściegów (podstawowa frakcja $40 \div 125 \mu \mathrm{m}$ ) Table V. The influence of flux powder with higher granularity addition on the microstructure of surfaced beads (main fraction $40 \div 125 \mu \mathrm{m}$ )

\begin{tabular}{|c|c|c|c|c|}
\hline \multirow{2}{*}{ Lp. } & \multicolumn{2}{|c|}{ Zawartość grubszej frakcji, \% mas. } & \multirow{2}{*}{$\begin{array}{l}\text { Natężenie } \\
\text { prądu, A }\end{array}$} & \multirow{2}{*}{$\begin{array}{c}\text { Charakterystyka mikrostruktury } \\
\text { napawanego ściegu }\end{array}$} \\
\hline & $200 \div 250 \mu \mathrm{m}$ & $315 \div 400 \mu \mathrm{m}$ & & \\
\hline 1 & - & - & $205-210$ & dendryty różnej długości, zorientowane w jednym kierunku \\
\hline 2 & 15 & - & $210-215$ & dendryty różnej długości, zorientowane w jednym kierunku \\
\hline 3 & 30 & - & $215-220$ & $\begin{array}{l}\text { drobne dendryty o różnej orientacji i drobna siatka węglików na gra- } \\
\text { nicach ziaren }\end{array}$ \\
\hline 4 & 45 & - & $220-225$ & dendryty nieduże oraz duże, zorientowane do zarodków krystalizacji \\
\hline 5 & - & 15 & $215-220$ & dendryty różnej długości, zorientowane w jednym kierunku \\
\hline 6 & - & 30 & $220-225$ & $\begin{array}{l}\text { drobne dendryty o różnej orientacji i drobna siatka węglików na gra- } \\
\text { nicach ziaren }\end{array}$ \\
\hline 7 & - & 45 & $225-230$ & Dendryty nieduże oraz duże, zorientowane do zarodków krystalizacj \\
\hline
\end{tabular}

proszku przez metal napawany: im więcej fazy a w proszku, tym więcej jej w napawanym metalu oraz w odpowiedniej proporcji zmienia się zawartość fazy y.

Ilość proszku, która może być podawana do łuku plazmowego i topić się w nim oraz jeziorku spawalniczym, zależy od parametrów napawania - ale nie wprost, jak np. przy napawaniu łukowym elektrodą topliwą.

Do badania wpływu ziarnistości proszku na strukturę napawanego metalu przeprowadzono plazmowe napawanie próbek proszkiem stali szybkotnącej PG10R6M5. Prędkość napawania - $12 \mathrm{~m} / \mathrm{h}$, prędkość podawania proszku - 4,2 kg/h. Stosowany proszek był

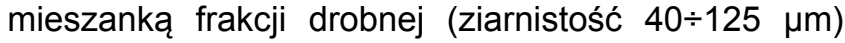
i frakcji o większej ziarnistości (składających się z dużych cząstek, grubszych) o różnym udziale (tabl. V).

Metal napawany proszkiem drobnych frakcji ma gruboziarnistą strukturę. Dodanie do niego 15\% proszku frakcji o większej ziarnistości nie powoduje szczególnych zmian struktury (tabl. V, oraz rys. 4a). Wynika z tego, że proszek drobnych frakcji roztapia się w łuku plazmowym i znacznie przegrzewa w jeziorku spawalniczym, w wyniku czego przy stygnięciu z wysokiej temperatury tworzą się duże dendryty (rys. 4a).

Przy zawartości ok. 30\% frakcji o ziarnistości $200 \div 250 \mu \mathrm{m}$ lub $315 \div 400 \mu \mathrm{m}$ struktura napawanego metalu wyraźnie rozdrabnia się, a siatka węglików staje się stosunkowo cienka (tabl. V, rys. 4b). Jeżeli porównywać mikrostrukturę napawanego metalu tego typu (rys. 4b) i proszku gruboziarnistego (rys. 3b), to są one


Rys. 4. Mikrostruktura napawanego metalu 10R6M5 (400x) przy wprowadzeniu proszku gruboziarnistego do proszku frakcji drobnej (tabl. V): a) napawanie mieszanką nr 2, b) napawanie mieszanką nr 3, c) napawanie mieszanką nr 4, d) nieroztopiona cząstka proszku

Fig. 4. Microstructure of surfaced metal 10R6M5 (400x) with addition of coarse grain into inferior figures (tabl. V): a) surfaced by composition 2 , b) surfaced by composition 3 , c) surfaced by composition 4 , d) non-molten element of flux powder 
podobne. Wynika z tego, że dodatek gruboziarnistej frakcji proszku prowadzi do sytuacji, że nie cały proszek roztapia się w łuku i jego część trafia do jeziorka spawalniczego nie całkiem roztopiona. Temperatura jeziorka spawalniczego nie osiąga poziomu równoważnego i napawany metal w większym stopniu dziedziczy strukture materiału dodatkowego - proszku.

Przy dalszym zwiększeniu udziału tych frakcji do $45 \%$ zachowuje się w zasadzie charakter struktury o różnej orientacji, lecz pojawiają się duże dendryty rosnące od zarodków krystalizacji, które stanowią duże cząstki proszku dotapiające się w jeziorku spawalniczym (rys. 4c). Jeżeli takie cząstki nie zdążą się całkowicie roztopić, to także występują jako zarodki krystalizacji (rys. 4d).

Charakter wpływu na strukturę napawanego metalu obydwu frakcji gruboziarnistych był w przybliżeniu jednakowy. Jednak przy dużym udziale $\geq 45 \%$ frakcji $315 \div 400 \mu \mathrm{m}$ w strukturze napawanego metalu znacznie częściej obserwuje się nieroztopione cząstki proszku.

\section{Wnioski}

Zastosowanie w drutach proszkowych do napawania łukowego materiałów wsadowych zawierających nanowymiarowe węgliki prowadzi do rozdrobnienia struktury napoiny i bardziej równomiernego rozkładu pierwiastków stopowych.

Stopiwo drutów proszkowych, których wsad zawiera nanowymiarowe węgliki, ma większą odporność na działanie ciepła i zużycie przy tarciu ślizgowym metal-metal.

Stwierdzono, że przy napawaniu plazmowo-proszkowym występuje efekt dziedziczenia struktury proszku PG-10R6M5 przez metal napawany: im więcej fazy a w zastosowanym proszku, tym więcej jej też w napawanym metalu, w odpowiedniej proporcji zmienia się również zawartość $y$-fazy w napawanym metalu. Na wymiary ziaren i charakter krystalizacji napawanego metalu wpływa skład frakcyjny i mikrostruktura proszku stanowiącego materiał dodatkowy.

Wpływ strukturalnej dziedziczności w największym stopniu przejawia się w tych metodach napawania, w których materiały dodatkowe nie przewodzą prądu i nie występuje bezpośrednie sprzężenie między natężeniem prądu łuku spawalniczego a wydajnością stapiania materiału dodatkowego.

\section{Literatura}

[1] Баум Б.А.: Металлические жидкости. Изд. Наука, M. 1979.

[2] Гиршович Н.Г., Иоффре А.Я., Зоммер Л.Р. и др.: Влияние природы шихтовых материалов на структуру и свойства чугуна с шаровидным и пластинчатым графитом. Основы образования литейных сплавов. Изд. Наука, M. 1970 s. $224-227$

[3] Никитин В.И.: Управление наследственностью структуры шихты и расплавов - важнейший резерв повышения качества отливок. Литейное производство. 1988. № 9. s. 5-6.

[4] Никитин В.И.: О влиянии качества шихтовых металлов на свойства легких сплавов. Цветные металлы. 1982. № 8 s. $73-75$.

[5] Прудовский П.П., Голяков В.Д., Симонова Н.А. и др. Влияние наследственности структуры шихты на механические свойства сплава ВАЛ8. Литейное производство. 1986. № 11 s. 7-8.

[6] Еланский Г.Н., Кудрин В.А.: Строение и свойства жидкого металла. Изд. Металлургия, М. 1984.

[7] Попель П.С., Баум Б.А.: Термодинамический анализ одной из причин металлургической наследственности. Известия АН СССР. Металлы. 1986. № 5. С. s. 47-51.

[8] Вилсон Д.Р.: Структура жидких металлов и сплавов. Изд. Металлургия, М. 1972.

[9] Татаринова Л.И.: Структура твердых аморфных и жидких веществ. М.: Наука, 1983.

[10] Крокстон К.: Физика жидкого состояния. Пер. с англ. Изд. Мир, М. 1978.
[11] Ватолин Н.А., Пастухов Э.А.: Дифракционные исследования строения высокотемпературных расплавов. Изд. Наука, М. 1980.

[12] Арсентьев П.П., Коледов Л.А.: Металлические расплавы и их свойства. Изд. Металлургия, М. 1976.

[13] Ершов Г.С., Черняков В.А.: Строение и свойства жидких и твердых металлов. Изд. Металлургия, М. 1978

[14] Белащенко Д.К.: Структура жидких и аморфных металлов. Изд. Металлургия, М. 1985.

[15] Ерохин А.А.: Основы сварки плавлением. Изд. Машиностроение, М. 1973.

[16] Лесков Г.И.: Электрическая сварочная дуга. Изд. Машиностроение, М. 1975.

[17] Фрумин И.И.: Автоматическая электродуговая наплавка. Изд. Металлургиздат, Харьков. 1961.

[18] Гладкий П.В., Переплетчиков Е.Ф., Рябцев И.А.: Плазменная наплавка. Изд. Экотехнология, Киев. 2007.

[19] Рябцев И.А., Кондратьев И.А., Гадзыра Н.Ф. и др.: Влияние ультрадисперсных карбидов в порошковых проволоках на свойства теплостойкого наплавленного металла. Автомат. сварка. 2009. № 6. С. s. 13-16.

[20] Рябцев И.И., Черняк Я.П., Осин В.В.: Блочно-модульная установка для испытаний наплавленного металла. Сварщик. 2004. № 1 s. 18-20.

[21] Рябцев И.А., Переплетчиков Е.Ф., Миц И.В., Бартенев И.А.: Влияние исходной структуры и гранулометрического состава порошка на структуру металла 10Р6М5, наплавленного плазменным способом. Автомат. сварка. 2007, № 10 s. 23-28. 